\title{
Predicting extraction and uptake of arterial energy metabolites by the mammary glands of lactating cows when blood flow is perturbed
}

\author{
J. P. Cant, ${ }^{* 1}$ T. G. Madsen, $†$ and S. R. L. Cieslar* \\ *Department of Animal Biosciences, University of Guelph, Ontario N1G 2W1, Canada \\ †Evonik Industries AG, Rodenbacher Chaussee 4, D-63457 Hanau-Wolfgang, Germany
}

\begin{abstract}
Previous work shows that mammary uptake of milk precursors from blood can be affected by the rate of blood flow $(\mathrm{F})$ to the glands. The purpose of the current work was to test the ability of compartmental and cylindrical capillary models to account for the variation in mammary extraction and net uptake of plasma metabolites produced by perturbation of mammary F. The data for model fitting were obtained from a previous experiment in which mammary arteriovenous differences of acetate $+\beta$-hydroxybutyrate $(2 \mathrm{C})$, glucose, triacylglycerol (TAG), and long-chain fatty acids (LCFA) were measured in 4 cows before, during, and after intraarterial infusion of inhibitors of endothelial nitric oxide synthase and cyclooxygenase, which are 2 major systems of $\mathrm{F}$ control in the mammary glands. The 4 models tested were (1) constant extraction within each cow, (2) clearance from an extracellular compartment is a linear function of $\mathrm{F}$ with an intercept, (3) total capillary volume in a cylindrical representation is a linear function of $\mathrm{F}$ with an intercept, and (4) uptake from an extracellular compartment obeys Henri-Michaelis-Menten kinetics, where maximum velocity $\left(\mathrm{V}_{\max }\right)$ is a linear function of $\mathrm{F}$ with an intercept. According to prediction errors, model 4 fitted $2 \mathrm{C}$ extraction data best, accounting for $82 \%$ of the observed variation. The estimated $\mathrm{K}_{\mathrm{m}}$ (Henri-Michaelis-Menten constant) for venous $2 \mathrm{C}$ was $0.4 \mathrm{~m} M$. For glucose clearance, a variant of model 2 with a positive effect of $2 \mathrm{C}$ uptake on clearance was identified as best, producing a coefficient of determination $\left(\mathrm{R}^{2}\right)$ of 0.31 . For TAG, model 2 with a positive effect of arterial TAG concentration on TAG clearance was best, with an $\mathrm{R}^{2}$ of 0.22 . For LCFA, model 2 with a positive effect of arterial LCFA on LCFA clearance was best, with an $\mathrm{R}^{2}$ of 0.29 . Models 2 and 3 fitted the extraction data with the same $\mathrm{R}^{2}$-values and prediction errors, so both compartmental and cylindrical approaches to describing the vascular
\end{abstract}

Received January 20, 2015.

Accepted September 23, 2015.

${ }^{1}$ Corresponding author: jcant@uoguelph.ca bed were equally capable of describing the effect of F on mammary uptakes. A combined fit of all bestfit models to extraction data for all 4 metabolites at once explained $52,42,73$, and $77 \%$ of variation in net uptakes of $2 \mathrm{C}$, glucose, TAG, and LCFA, respectively. According to the fitted model, each $1 \mathrm{~L} / \mathrm{min}$ increase in $\mathrm{F}$ increased the mammary volumes of distribution of $2 \mathrm{C}$, glucose, TAG, and LCFA by 13, 14, 18, and 7\%, respectively.

Key words: mammary blood flow, dairy cow, mammary uptake, modeling

\section{INTRODUCTION}

Nutrient utilization by the mammary glands of lactating ruminants is particularly suited to study by arteriovenous difference methodology because of venous drainage through an easily accessible vein, and secretion of biosynthetic products through a separate network of epithelial ducts (Linzell, 1974). The difference between arterial $\left([\mathbf{S}]_{\mathbf{A}}\right)$ and venous $\left([\mathbf{S}]_{\mathbf{V}}\right)$ concentrations of a metabolite (substrate $\mathrm{S}$ ) gives rise to an estimate of net uptake when plasma flow rate $(\mathbf{F})$ is taken into account, according to the Fick equation:

$$
\text { uptake }=\left([\mathrm{S}]_{\mathrm{A}}-[\mathrm{S}]_{\mathrm{V}}\right) \mathrm{F} .
$$

The balance between net uptakes of milk precursors and their outputs in milk products is assumed to indicate utilization in catabolic pathways. Quantifying net anabolic and catabolic utilization of each milk precursor from one set of blood and milk samples produces a relatively complete view of mammary metabolite fluxes, and the technique has been widely used to explain how perturbations in diet and physiological state elicit changes in production and composition of milk from dairy ruminants (e.g., Linzell and Mepham, 1974; Cant et al., 1993; Mackle et al., 2000; Delgado-Elorduy et al., 2002; Lemosquet et al., 2009; Safayi and Nielsen, 2013).

Decades of measurement of mammary arteriovenous differences have spawned attempts to accurately predict rates of net uptake of milk precursors from blood as a test of understanding of the underlying mechanisms. 
A

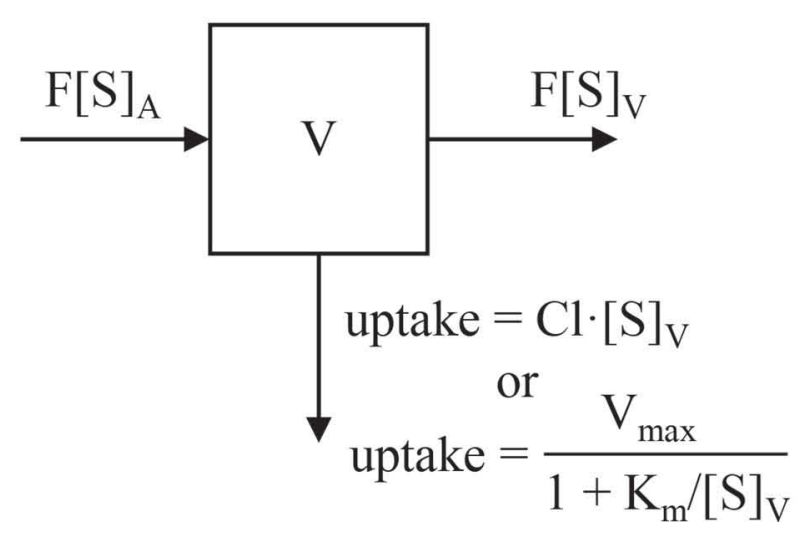

B

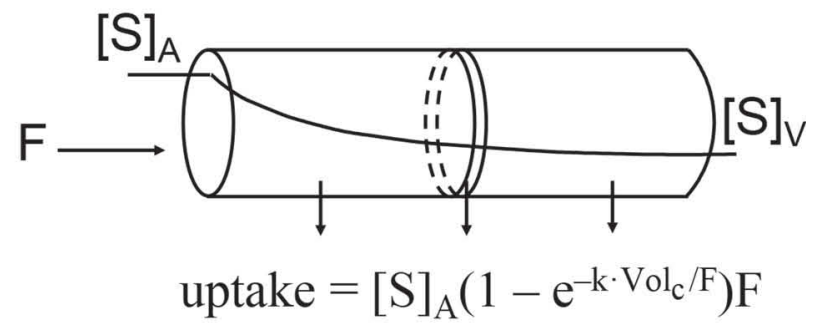

Figure 1. Flow diagrams for (A) compartmental, and (B) cylindrical capillary models. $\mathrm{Cl}=$ clearance, $\mathrm{F}=$ flow, $\mathrm{K}_{\mathrm{m}}=\mathrm{Henri-Michaelis-}$

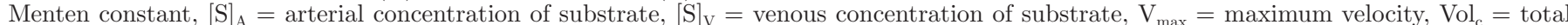
capillary volume.

One of the questions that has arisen is how to accommodate a change in mammary blood flow (MBF) in the prediction of nutrient uptake from blood. Mammary blood flow is affected by changes in hormonal or nutritional state (Linzell, 1974; Davis and Collier, 1985; Cant et al., 1993; Bequette et al., 2000; Mackle et al., 2000; Rigout et al., 2002) because of local vasodilator release from cells of the mammary glands (Nielsen et al., 1995, 2004; Cieslar et al., 2014). Recently, Madsen et al. (2014) showed that inhibition of mammary vasodilatory systems to decrease blood flow through the glands caused decreases in mammary uptakes of acetate, glucose, and long-chain fatty acids (LCFA). A compartmental model of the uptake process provides a framework to accommodate this effect of MBF. If the extracellular fluid of the mammary glands is considered to be a well-mixed compartment (Figure 1A), according to Hanigan et al. (1998), then

$$
\text { uptake }=\mathrm{Cl} \cdot[\mathrm{S}]_{\mathrm{V}},
$$

where clearance $(\mathbf{C l})$ is a product of first-order transport efficiency $(\mathbf{k})$ and volume of the compartment $\left(\mathrm{Vol}_{\mathrm{e}}\right)$ :

$$
\mathrm{Cl}=\mathrm{k} \cdot \mathrm{Vol}_{\mathrm{e}}
$$

In addition to decreased nutrient uptakes when MBF is depressed, Madsen et al. (2014) also reported that $\mathrm{Cl}$ values decreased, and it was proposed that closing capillaries to flow, due to vasodilator inhibition, decreased the apparent volume of distribution of arterially delivered nutrients into the extracellular fluid of the mammary glands. Thus, the effect of MBF on uptake could be accommodated by setting $\mathrm{Vol}_{\mathrm{e}}$ as a function of $\mathrm{F}$, and calculating uptake according to Eq. [3] and [2].

An alternative to the well-mixed compartmental model is the Krogh cylinder model, in which each capillary is considered a cylinder through which blood flows and along the length of which net uptake occurs (Figure 1B). Among many parallel capillaries, the average transit time of blood from arterial to venous end is equal to the ratio of total capillary volume $\left(\mathbf{V o l}_{\mathbf{c}}\right)$ to $\mathrm{F}$. Thus, as derived in Cant and McBride (1995),

$$
[\mathrm{S}]_{\mathrm{V}}=[\mathrm{S}]_{\mathrm{A}} \mathrm{e}^{-\mathrm{k} \cdot \mathrm{Vol}_{\mathrm{c}} / \mathrm{F}},
$$

and, substituting Eq. [4] into Eq. [1],

$$
\text { uptake }=[\mathrm{S}]_{\mathrm{A}}\left(1-\mathrm{e}^{-\mathrm{k} \cdot \mathrm{Vol}_{\mathrm{c}}} / \mathrm{F}\right) \mathrm{F} \text {. }
$$

Again, $\mathrm{Vol}_{\mathrm{c}}$ could be set as a function of $\mathrm{F}$, and Eq. [5] could be used to describe a positive relationship between MBF and uptake of milk precursors.

The purpose of the current work was to test the ability of compartmental and cylindrical models to account for the variation in mammary uptake of plasma metabolites produced by MBF perturbation in the experiment of Madsen et al. (2014) and to parameterize deterministic equations that describe effects of $[\mathrm{S}]_{\mathrm{A}}$ and $\mathrm{F}$ on net mammary uptakes. Inputs to the models are $[\mathrm{S}]_{\mathrm{A}}$ and F. However, uptake and clearance are both estimated from $\mathrm{F}$ and would thus be expected to exhibit correlations with $\mathrm{F}$ unrelated to the accuracy and precision of predictive equations using $\mathrm{F}$ as an input. Similarly, $[\mathrm{S}]_{\mathrm{V}}$ and arteriovenous difference are both highly related to 
$[\mathrm{S}]_{\mathrm{A}}$ and yield overly optimistic statistics of goodness of fit. Alternatively, extraction, defined as follows

$$
\text { extraction }=\frac{[\mathrm{S}]_{\mathrm{A}}-[\mathrm{S}]_{\mathrm{V}}}{[\mathrm{S}]_{\mathrm{A}}},
$$

is an arteriovenous difference corrected for $[\mathrm{S}]_{\mathrm{A}}$ and is measured independent of F. Thus, of all the independent variables representing nutrient uptake by the mammary glands, extraction was considered the most robust for testing predictive accuracy of a model using $[\mathrm{S}]_{\mathrm{A}}$ and $\mathrm{F}$ as inputs. In addition to explaining variation in a truly independent variable, fitting models to extraction data generated parameters that predicted net uptakes across the mammary glands with a reasonable degree of accuracy.

\section{MATERIALS AND METHODS}

\section{Observations}

Observations for model fitting were obtained from 4 lactating cows subjected to infusion of inhibitors of $\mathrm{NO}$ synthase (NOS) and cyclooxygenase (COX) into the external iliac artery supplying one udder half. Treatments were infused for $1 \mathrm{~h}$ each day in a $4 \times 4$ Latin square design and consisted of saline, NOS inhibitor, COX inhibitor, or a combination of NOS + COX inhibitors. Iliac plasma flow was measured by arteriovenous dye dilution at 24 and 9 min before, 29 and 44 min during, and 50 and 80 min after infusion, respectively. In these same arterial and venous samples, concentrations of acetate, BHB, glucose, and triacylglycerol (TAG) were measured as described (Madsen et al., 2014). Because acetate and BHB are both sequestered in mammary cells by identical pathways involving metabolism of 2-C units, they were considered in aggregate for the model analyses as acetate +2 . BHB $(\mathbf{2 C})$. In addition, concentrations of fatty acids were measured by enzymelinked spectrophotometry (NEFA C kit, Wako Chemicals GmbH, Neuss, Germany). Arteriovenous differences and uptakes of TAG represent extracellular hydrolysis by lipoprotein lipase (LPL). Inputs of long-chain fatty acids (LCFA) to the extracellular compartment for transport into mammary cells can thus be calculated from the micromolar arteriovenous differences of TAG and arterial concentrations of fatty acids as

$$
\mathrm{LCFA}_{\mathrm{A}}=3\left([\mathrm{TAG}]_{\mathrm{A}}-[\mathrm{TAG}]_{\mathrm{V}}\right)+[\text { fatty acids }]_{\mathrm{A}} \cdot[7]
$$

Because Madsen et al. (2014) measured TAG as total glycerides, which includes free glycerol, $\mathrm{LCFA}_{\mathrm{A}}$ is an overestimation. Arteriovenous differences, extractions, and uptakes of LCFA were calculated using Eq. [7] for the arterial concentration.

Results of the inhibitor experiment were presented by Madsen et al. (2014). Briefly, the inhibitors caused up to $50 \%$ depression in iliac plasma flow compared with saline, arterial concentrations of acetate, BHB, and glucose became elevated, and extraction across the mammary glands was elevated in some cases and not affected in others. The data set for model-fitting purposes consisted of all 6 observations before, during, and after infusion from each cow.period for a total of 96 observations. Raw observations were used and not adjusted for nondeterministic variables such as cow, period, or treatment. Means and ranges of observed values are shown in Table 1.

\section{Models}

From inputs of $[\mathrm{S}]_{\mathrm{A}}$ and $\mathrm{F}$, uptakes and extractions of $2 \mathrm{C}$, glucose, TAG, and LCFA were predicted using 4 different models based on the nutrient flows depicted in Figure 1. Each model accommodates effects of $[\mathrm{S}]_{\mathrm{A}}$ and $\mathrm{F}$ in a different way, as summarized in Table 2 . The models and their resultant extraction equations for fitting to data were derived as follows.

Model 1 is a compartmental model (Figure 1A) where Eq. [2] and [3] describe uptake, and $\mathrm{Vol}_{\mathrm{e}}$ is directly related to $\mathrm{F}$ according to slope $\mu_{1}$, such that $\mathrm{Cl}=\mathrm{k} \mu_{1} \mathrm{~F}$. The terms $\mathrm{k}$ and $\mu_{1}$ are not separable so they were aggregated into slope $b_{1}$, so that

$$
\mathrm{Cl}=\mathrm{b}_{1} \mathrm{~F}
$$

as shown in Table 2. The steady-state $[\mathrm{S}]_{\mathrm{V}}$ predicted by model 1 was obtained by setting Eq. [1] = Eq. [2] to yield

$$
[\mathrm{S}]_{\mathrm{V}}=\frac{\mathrm{F}[\mathrm{S}]_{\mathrm{A}}}{\mathrm{Cl}+\mathrm{F}}
$$

Extraction (Eq. [6]) is thus

$$
\text { extraction }=\frac{\mathrm{Cl}}{\mathrm{Cl}+\mathrm{F}} \text {, }
$$

which becomes, for model 1 (Eq. [8]),

$$
\text { extraction }=\frac{\mathrm{b}_{1}}{\mathrm{~b}_{1}+1} \text {. }
$$

Extraction is constant in this model. 
Table 1. Means, SD, and ranges of observations in the data set used to fit extraction models

\begin{tabular}{lcccc}
\hline Item $^{1}$ & Mean & SD (\% of mean) & Minimum & Maximum \\
\hline Iliac plasma flow (L/min) & 5.60 & 26.6 & 2.07 & 8.30 \\
Arterial concentration & & & & \\
Acetate $(\mathrm{m} M)$ & 2.10 & 60.7 & 0.95 & 6.66 \\
BHB $(\mathrm{m} M)$ & 1.17 & 70.8 & 0.36 & 3.64 \\
2C $(\mathrm{m} M)$ & 4.47 & 63.5 & 1.80 & 13.74 \\
Glucose $(\mathrm{m} M)$ & 3.19 & 24.1 & 2.06 & 6.51 \\
Fatty acids $(\mu M)$ & 150 & 61.5 & 58 & 565 \\
TAG $(\mu M)$ & 44 & 18.1 & 33 & 71 \\
LCFA $(\mu M)$ & 192 & 51.0 & 64 & 624 \\
Extraction & & & & 0.13 \\
Acetate & 0.61 & 33.3 & 0.02 & 0.57 \\
BHB & 0.31 & 40.7 & 0.10 & 0.70 \\
2C & 0.46 & 36.0 & 0.09 & 0.54 \\
Glucose & 0.26 & 32.2 & 0.04 & 0.52 \\
TAG & 0.30 & 25.6 & 0.16 & 0.62 \\
LCFA & 0.40 & 25.0 & \\
\hline
\end{tabular}

${ }^{1} 2 \mathrm{C}=$ acetate $+\beta$-hydroxybutyrate; TAG $=$ triacylglycerol; LCFA = long-chain fatty acids.

Model 2 is a variant of the compartmental model in which $\mathrm{Vol}_{\mathrm{e}}$ is nonzero at $\mathrm{F}=0$; that is, there is an intercept $\left(\mathrm{b}_{0}\right)$, such that

$$
\mathrm{Cl}=\mathrm{b}_{0}+\mathrm{b}_{1} \mathrm{~F} \text {. }
$$

Thus,

$$
\text { extraction }=\frac{\mathrm{b}_{0}+\mathrm{b}_{1} \mathrm{~F}}{\mathrm{~b}_{0}+\mathrm{b}_{1} \mathrm{~F}+\mathrm{F}}
$$

Additional variables were included in linear regression model 2 for prediction of glucose, TAG, and LCFA ex- tractions, and these models were designated $2 \mathrm{a}, \mathrm{b}$, and c (Table 2).

Model 3 is based on the Krogh cylinder (Eq. [5]), where the number of open capillaries determines F, so total capillary $\mathrm{Vol}_{\mathrm{c}}$ is a linear function of $\mathrm{F}$, such that

$$
\mathrm{k} \cdot \mathrm{Vol}_{\mathrm{c}}=\mathrm{b}_{0}+\mathrm{b}_{1} \mathrm{~F} .
$$

Substitution of Eq. [14] into Eq. [4] and then solving Eq. [6] yields the extraction equation for model 3:

$$
\text { extraction }=1-e^{-\left(\frac{\mathrm{b}_{0}}{\mathrm{~F}}+\mathrm{b}_{1}\right)} \text {. }
$$

\begin{tabular}{|c|c|c|c|c|}
\hline $\begin{array}{l}\text { Model } \\
\text { no. }\end{array}$ & Uptake & Effect of $\mathrm{F}$ & Extraction & $\begin{array}{l}\text { Fitted } \\
\text { parameters }\end{array}$ \\
\hline 1 & $\mathrm{Cl} \cdot[\mathrm{S}]_{\mathrm{V}}$ & $\mathrm{Cl}=\mathrm{b}_{1} \mathrm{~F}$ & $\frac{\mathrm{Cl}}{\mathrm{Cl}+\mathrm{F}}$ & $\mathrm{b}_{1}$ \\
\hline 2 & $\mathrm{Cl} \cdot[\mathrm{S}]_{\mathrm{V}}$ & $\mathrm{Cl}=\mathrm{b}_{0}+\mathrm{b}_{1} \mathrm{~F}$ & $\frac{\mathrm{Cl}}{\mathrm{Cl}+\mathrm{F}}$ & $\mathrm{b}_{0}, \mathrm{~b}_{1}$ \\
\hline $2 \mathrm{a}$ & $\mathrm{Cl} \cdot[\mathrm{S}]_{\mathrm{V}}$ & $\mathrm{Cl}=\mathrm{b}_{0}+\mathrm{b}_{1} \mathrm{~F}+\mathrm{b}_{2}\left(\mathrm{up}_{2 \mathrm{C}}\right)$ & $\frac{\mathrm{Cl}}{\mathrm{Cl}+\mathrm{F}}$ & $\mathrm{b}_{0}, \mathrm{~b}_{1}, \mathrm{~b}_{2}$ \\
\hline $2 \mathrm{c}$ & $\mathrm{Cl} \cdot[\mathrm{S}]_{\mathrm{V}}$ & $\mathrm{Cl}=\mathrm{b}_{0}+\mathrm{b}_{1} \mathrm{~F}+\mathrm{b}_{2}[\mathrm{LCFA}]_{\mathrm{A}}$ & $\frac{\mathrm{Cl}}{\mathrm{Cl}+\mathrm{F}}$ & $\mathrm{b}_{0}, \mathrm{~b}_{1}, \mathrm{~b}_{2}$ \\
\hline 3 & & $\mathrm{k} \cdot \operatorname{Vol}_{\mathrm{c}}=\mathrm{b}_{0}+\mathrm{b}_{1} \mathrm{~F}$ & & $\mathrm{~b}_{0}, \mathrm{~b}_{1}$ \\
\hline 4 & $\mathrm{~V}_{\max } /\left(1+\mathrm{K}_{\mathrm{m}} /[\mathrm{S}]_{\mathrm{V}}\right)$ & $\mathrm{V}_{\max }=\mathrm{b}_{0}+\mathrm{b}_{1} \mathrm{~F}$ & $1+\frac{\mathrm{V}_{\max }+\mathrm{K}_{\mathrm{m}} \mathrm{F}-[\mathrm{S}]_{\mathrm{A}} \mathrm{F}-\sqrt{\left(\mathrm{V}_{\max }+\mathrm{K}_{\mathrm{m}} \mathrm{F}-[\mathrm{S}]_{\mathrm{A}} \mathrm{F}\right)^{2}+4[\mathrm{~S}]_{\mathrm{A}} \mathrm{F}^{2} \mathrm{~K}_{\mathrm{m}}}}{2[\mathrm{~S}]_{\mathrm{A}} \mathrm{F}}$ & $\mathrm{b}_{0}, \mathrm{~b}_{1}, \mathrm{~K}_{\mathrm{m}}$ \\
\hline
\end{tabular}

Table 2. Uptake and extraction equations that were fitted to metabolite extraction data for models 1 to $4^{1}$ 


$$
\begin{gathered}
{[S]_{\mathrm{V}}=\frac{-\mathrm{b}_{0}-\mathrm{b}_{1} \mathrm{~F}-\mathrm{K}_{\mathrm{m}} \mathrm{F}+[\mathrm{S}]_{\mathrm{A}} \mathrm{F}+\sqrt{\left(\mathrm{b}_{0}+\mathrm{b}_{1} \mathrm{~F}+\mathrm{K}_{\mathrm{m}} \mathrm{F}-[\mathrm{S}]_{\mathrm{A}} \mathrm{F}\right)^{2}+4[\mathrm{~S}]_{\mathrm{A}} \mathrm{F}^{2} \mathrm{~K}_{\mathrm{m}}}}{2 \mathrm{~F}} .} \\
\text { extraction }=1+\frac{\mathrm{b}_{0}+\mathrm{b}_{1} \mathrm{~F}+\mathrm{K}_{\mathrm{m}} \mathrm{F}-[\mathrm{S}]_{\mathrm{A}} \mathrm{F}-\sqrt{\left(\mathrm{b}_{0}+\mathrm{b}_{1} \mathrm{~F}+\mathrm{K}_{\mathrm{m}} \mathrm{F}-[\mathrm{S}]_{\mathrm{A}} \mathrm{F}\right)^{2}+4[\mathrm{~S}]_{\mathrm{A}} \mathrm{F}^{2} \mathrm{~K}_{\mathrm{m}}}}{2[\mathrm{~S}]_{\mathrm{A}} \mathrm{F}} .
\end{gathered}
$$

Model 4 is a compartmental model with saturable net uptake by the mammary glands, instead of first-order clearance, according to the Henri-Michaelis-Menten equation:

$$
\text { uptake }=\frac{\mathrm{V}_{\max }}{1+\mathrm{K}_{\mathrm{m}} /[\mathrm{S}]_{\mathrm{V}}},
$$

where $\mathbf{V}_{\max }$ is the maximum velocity, and $\mathbf{K}_{\mathrm{m}}$ is the Henri-Michaelis-Menten constant. Here, there is no explicit representation of the volume of the extracellular compartment but a change in $\mathrm{Vol}_{\mathrm{e}}$ associated with a change in $\mathrm{F}$ would affect the number of cells exposed to substrate; that is, apparent $\mathrm{V}_{\max }$. Thus, $\mathrm{V}_{\max }$ is assumed a linear function of $\mathrm{F}$ according to

$$
\mathrm{V}_{\max }=\mathrm{b}_{0}+\mathrm{b}_{1} \mathrm{~F} .
$$

The steady-state $[\mathrm{S}]_{\mathrm{V}}$ predicted by model 4 was obtained by substituting Eq. [17] into Eq. [16], setting the result equal to Eq. [1], and solving to yield Eq. [18], see above.

Extraction (Eq. [6]) is thus Eq. [19], see above.

\section{Statistical Methods}

To identify potential variables for inclusion in the mechanistic uptake models for prediction of mammary extraction, preliminary regression analysis was conducted where a stepwise algorithm was employed in PROC REG of SAS (version 9; SAS Institute Inc., Cary, NC) to select, from the observed iliac plasma flows and metabolite uptakes, those variables that contributed with $P \leq 0.05$ to variation in uptake and clearance of $2 \mathrm{C}$, glucose, TAG, or LCFA.

Extraction Eq. [11], representing model 1, was fitted to observations $\left(O_{i j}\right)$ by using Solver in Excel (Microsoft Corp., Redmond, WA) to find the value of $b_{1}$ for each cow that minimized residual sum of squares (RSS) for each metabolite, where RSS $=\sum_{i=1}^{4} \sum_{j=1}^{n_{i}}\left(P_{i j}-O_{i j}\right)^{2}, n_{i}$ is the number of observations per $i$ th cow for that metabolite, and $P_{i j}$ are the predictions. Extraction equa- tions [13], [15], and [19], representing models 2, 3, and 4 , respectively, were fitted to observations by using PROC NLIN of SAS to find values of $b_{0}, b_{1}, b_{2}$, and $K_{m}$ that minimized RSS for each metabolite across all cows. To test for the presence of multicollinearity in the multivariate models, variance inflation factors were calculated for each set of predictors as $\left(1-R_{k}^{2}\right)^{-1}$, where $R_{k}^{2}$ is the coefficient of determination for regression of one predictor on all others (Neter et al., 1985). The highest variance inflation factor obtained was 1.8 , indicating an absence of multicollinearity affecting interpretation of parameter estimates.

Different sets of parameters for each cow were not estimated for models 2,3 , and 4 because the primary goal of the research was to evaluate methods to use $\mathrm{F}$ in deterministic predictions of uptake and it was assumed that the effects of a unit change in $\mathrm{F}$ on $\mathrm{Vol}_{\mathrm{e}}$ or $\mathrm{Vol}_{\mathrm{c}}$ should be identical across all cows. Furthermore, 4 cows was considered an insufficient sample size to obtain meaningful estimates of the mean and variance of potentially cow-specific parameters such as $b_{0}$ or $V_{\max }$. Preliminary cow-specific fits using PROC NLMIXED did not improve prediction errors over the PROC NLIN fits, and parameter estimates were often not different. Thus, a set of parameters for each model was sought that could explain variation both within and between cows, and the ability to do so was evaluated by partitioning residual variation. A pseudo-coefficient of determination $\left(\mathrm{R}^{2}\right)$ representing the proportion of variation accounted for by fitted models was calculated for each metabolite fit as $1-\mathrm{RSS} /$ total sum of squares (TSS) where TSS $=\sum_{i=1}^{4} \sum_{j=1}^{n_{i}}\left(O_{i j}-\bar{O}_{. .}\right)^{2}$. Variation between and within cows was split to calculate

$$
\text { pseudo-r }{ }^{2} \text { between cows }=1-\frac{\sum_{i=1}^{4}\left(\bar{P}_{i .}-\bar{O}_{i .}\right)^{2} n_{i}}{\sum_{i=1}^{4}\left(\bar{O}_{i .}-\bar{O}_{. . .}\right)^{2} n_{i}},
$$

representing the similarity of the mean prediction for each cow to the mean observation for each cow, and 
pseudo-r ${ }^{2}$ within cows $=1-\frac{\sum_{i=1}^{4} \sum_{j=1}^{n_{i}}\left(P_{i j}-O_{i j}-\bar{P}_{i .}+\bar{O}_{i .}\right)^{2}}{\sum_{i=1}^{4} \sum_{j=1}^{n_{i}}\left(O_{i j}-\bar{O}_{i .}\right)^{2}}$,

representing the similarity of predictions within each cow to observations within each cow. Fitting model 1, which generates a constant extraction, to each cow individually yields a predicted extraction equal to the mean observed extraction, and thus accounts for $100 \%$ of the between-cow variation. These model 1 fits provided a standard against which to compare the statistics of the other candidate model fits across all cows. Mean square prediction errors (MSPE) were calculated for each fit as $R S S / \sum_{i=1}^{4} n_{i}$, and the square root of MSPE is referred to as residual or prediction error. Pearson correlation coefficients between observed and predicted extractions of each metabolite were calculated and multiplied by the bias correction factor of Lin (1989) to produce a concordance correlation coefficient (CCC), representing both precision and accuracy of the predictions.

After the best-fitting models for each of the metabolites had been identified by statistical analysis, a combined fit to all metabolite extractions at once was performed because models $2 \mathrm{a}$ and $2 \mathrm{c}$ use $2 \mathrm{C}$ uptake and $[\mathrm{TAG}]_{\mathrm{V}}$ as inputs, which are predicted values. Thus, there is an interdependence between the metabolites that could skew parameter estimates if extraction data were fit one metabolite at a time. The full model is given in the Appendix. The combined fitting was conducted using Excel Solver (Microsoft Corp.) to minimize the total RSS for all metabolites, weighted by TSS for each metabolite $(j)$, as $\sum_{j=1}^{n}\left(R S S_{j} / T S S_{j}\right)$. From all 384 observations, 12 parameters were estimated by the procedure, consisting of $b_{0}$ and $b_{1}$ for each metabolite, $\mathrm{K}_{\mathrm{m}}$ for $2 \mathrm{C}$, and $\mathrm{b}_{2}$ for glucose, TAG, and LCFA. The Shapiro-Wilk test for normality of residuals was conducted using PROC UNIVARIATE of SAS.

\section{RESULTS AND DISCUSSION}

\section{C}

Variables that stepwise linear regression selected as accounting for variation in $2 \mathrm{C}$ uptake were $\mathrm{F}$ (coefficient $=0.97$; partial $\mathrm{R}^{2}=0.39$ ), glucose uptake (coefficient $=0.65$; partial $\mathrm{R}^{2}=0.12$ ), and $[2 \mathrm{C}]_{\mathrm{A}}$ (coefficient $=0.23$; partial $\left.\mathrm{R}^{2}=0.05\right)$. Variation in $2 \mathrm{C}$ clearance was related to $[2 \mathrm{C}]_{\mathrm{A}}$ (coefficient $=-0.75$; partial $\mathrm{R}^{2}=$ 0.57 ), glucose uptake (coefficient $=0.53$; partial $R^{2}=$ 0.06 ), LCFA uptake (coefficient $=-0.0024$; partial $\mathrm{R}^{2}$ $=0.03$ ), and $\mathrm{F}$ (coefficient $=0.57$; partial $\mathrm{R}^{2}=0.02$ ). These results were used to decide how mechanistic uptake equations should be formulated. Positive effects of $\mathrm{F}$ and $[2 \mathrm{C}]_{\mathrm{A}}$ on $2 \mathrm{C}$ uptake are accommodated by all 4 of the mechanistic models under evaluation. The negative effect of $[2 \mathrm{C}]_{\mathrm{A}}$ on $2 \mathrm{C}$ clearance suggests saturation, where efficiency of uptake decreases at higher $[2 \mathrm{C}]_{\mathrm{A}}$ values. The positive relationship between glucose uptake and $2 \mathrm{C}$ uptake or clearance was accommodated in the glucose model and will be discussed in the following section. The negative relationship between LCFA uptake and $2 \mathrm{C}$ clearance was ignored in the mechanistic modeling because it explained only $3 \%$ of the variation in $2 \mathrm{C}$ clearance and was not a significant predictor of $2 \mathrm{C}$ uptake.

Table 3 shows that a constant extraction for each cow accounted for $67 \%$ of the variation in observed extraction, and residual error was $20.6 \%$ of the mean observed value. Models 2 and 3 were unable to account for the variation between cows. In contrast, model 4, with saturable Henri-Michaelis-Menten kinetics, best described the variation in $2 \mathrm{C}$ extraction. This finding is consistent with the negative relationship between arterial concentration and clearance of $2 \mathrm{C}$ obtained by multiple regression. Overall, $98 \%$ of the variation between cows and $49 \%$ of the variation within cows was accounted for by model 4. Eighty-two percent of the total variation between and within cows was accounted for, and residual error decreased to $15.2 \%$ of the mean (Table 3 ). The CCC was high, at 0.90 , with very little bias correction. In preliminary work not shown, fits to extractions of acetate and BHB separately, instead of the combined variable $2 \mathrm{C}$, were obtained and they both displayed this saturation behavior.

One goal of the modeling was to find parameters that describe net mammary uptakes of metabolites from plasma. The estimated $\mathrm{K}_{\mathrm{m}}$ of $0.44 \mathrm{mM}$ for $2 \mathrm{C}$ sequestered by the mammary glands is lower than in vitro estimates of 1.22 and $1.79 \mathrm{mM}$ for conversion of extracellular acetate to fatty acids and $\mathrm{CO}_{2}$, respectively, by mammary tissue slices (Forsberg et al., 1984). Observed $[2 \mathrm{C}]_{\mathrm{V}}$ values in our data set ranged from 0.69 to 11.3 $\mathrm{m} M$, with a mean of $2.8 \mathrm{~m} M$, so uptakes predicted from either the in vivo or in vitro $\mathrm{K}_{\mathrm{m}}$ values would be in the saturating part of the curve, approaching $\mathrm{V}_{\max }$.

\section{Glucose}

According to multiple linear regression, variables that accounted for variation in glucose uptake with $P \leq 0.05$ were $2 \mathrm{C}$ uptake (coefficient $=0.33$, partial $\mathrm{R}^{2}=0.33$ ), 
[glucose $]_{\mathrm{A}}$ (coefficient $=0.82$, partial $\mathrm{R}^{2}=0.12$ ), and $\mathrm{F}$ (coefficient $=0.22$, partial $\mathrm{R}^{2}=0.02$ ). Variation in glucose clearance was significantly related to $2 \mathrm{C}$ uptake (coefficient $=0.20$, partial $\mathrm{R}^{2}=0.51$ ) only. All of the candidate uptake models (Table 2) include effects of $[\mathrm{S}]_{\mathrm{A}}$ and $\mathrm{F}$. The variance in common between glucose and $2 \mathrm{C}$ uptakes has been attributed to the use of glucose for NADPH synthesis in support of lipogenesis from 2C (Forsberg et al., 1984; Miller et al., 1991). Production of NADPH from glucose is driven by NADP produced in lipogenesis (Kather et al., 1972) so we chose to describe the covariance as an effect of $2 \mathrm{C}$ uptake on glucose uptake, rather than the reverse. Thus, $2 \mathrm{C}$ uptake was added as an independent variable to models 2 and 4 to yield model 2a:

$$
\mathrm{Cl}=\mathrm{b}_{0}+\mathrm{b}_{1} \mathrm{~F}+\mathrm{b}_{2}\left(\text { uptake }_{2 \mathrm{C}}\right),
$$

and model 4a:

$$
\mathrm{V}_{\max }=\mathrm{b}_{0}+\mathrm{b}_{1} \mathrm{~F}+\mathrm{b}_{2}\left(\text { uptake }_{2 \mathrm{C}}\right) .
$$

Accounting for all of the between-cow variation with a constant glucose extraction for each cow explained $22 \%$ of the variation in observed extraction efficiency and yielded a prediction error equal to $28.3 \%$ of the mean extraction (Table 4). Models 2 and 3 were only able to account for $34 \%$ of the variation between cows, with total $\mathrm{R}^{2}$ values of 0.13 and prediction errors equal to $30 \%$ of the mean. Henri-Michaelis-Menten kinetics in model 4 did not improve the fit, but including an effect of $\mathrm{C} 2$ uptake on clearance (model $2 \mathrm{a}$ ) or $\mathrm{V}_{\max }$ (model 4a) increased the $R^{2}$ and decreased the prediction error. In total, $73 \%$ of variation between cows and $19 \%$ of variation within cows was accounted for by model 2a. A higher proportion of variation between cows was explained by model 4a, but a lower proportion of variation within cows was explained.

Model 4a with 4 parameters did not substantially improve MSPE or $\mathrm{R}^{2}$ compared with model 2a with 3 parameters. The $\mathrm{K}_{\mathrm{m}}$ of $5.7 \mathrm{~m} M$ estimated with model 4a was also above the highest [glucose] $]_{\mathrm{V}}$ of $4.4 \mathrm{mM}$ in the data set, indicating that the linear part of the Henri-Michaelis-Menten curve was being used in the predictions. Similarly, mammary sequestration of glucose given as a bolus dose into the arterial circulation followed linear kinetics up to $7 \mathrm{~m} M$ [glucose $]_{\mathrm{A}}$ (Qiao et al., 2005b). In vitro estimates of 3.4 and $4.7 \mathrm{mM}$ for the $\mathrm{K}_{\mathrm{m}}$ of extracellular glucose utilization for lactose synthesis (Forsberg et al., 1985; Xiao and Cant, 2005), which is the main pathway of glucose sequestration in mammary epithelial cells, also support the appearance of linear kinetics within the physiological range of [glu$\operatorname{cose}_{\mathrm{V}}$. Thus, linear model $2 \mathrm{a}$ was chosen as the best model to predict glucose extraction. The bias correction factor for the CCC was 0.85 (Table 4), indicating slight bias. The CCC was low, however, because of a Pearson correlation coefficient of 0.55 between predicted and observed extraction.

\section{TAG}

Stepwise regression identified $\mathrm{F}$ (coefficient $=15$, partial $\left.R^{2}=0.43\right)$ and $[\mathrm{TAG}]_{\mathrm{A}}$ (coefficient $=3.0$, par-

Table 3. Parameters and statistics of best fits of models 1 to 4 to $2 \mathrm{C}$ (acetate $+\beta$-hydroxybutyrate) extraction data from 4 cows $(n=96)$

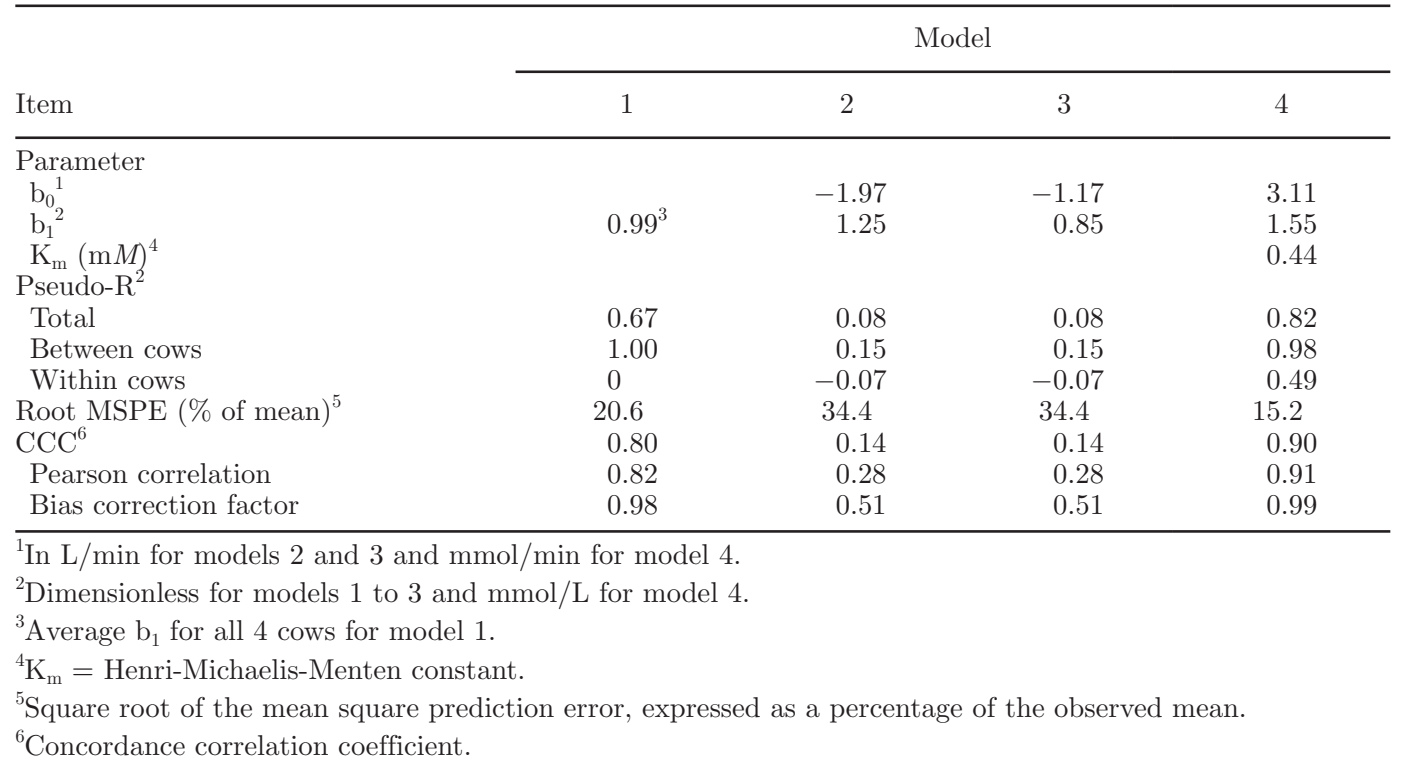


tial $\left.\mathrm{R}^{2}=0.28\right)$ as significant predictors of TAG uptake, and $\mathrm{F}$ (coefficient $=0.51$, partial $\mathrm{R}^{2}=0.33$ ) and [TAG] A (coefficient $=0.062$, partial $\left.R^{2}=0.20\right)$ as significant predictors of TAG clearance. The positive clearance coefficient on $[\mathrm{TAG}]_{\mathrm{A}}$ lies in contrast to the negative relationship between $[2 \mathrm{C}]_{\mathrm{A}}$ and $2 \mathrm{C}$ clearance that signified saturation kinetics. Here, the positive coefficient is a consequence of a relationship between TAG uptake and $[\mathrm{TAG}]_{\mathrm{A}}$ that exhibits low uptakes at relatively high $[\mathrm{TAG}]_{\mathrm{A}}$.

One approach to accommodate low uptakes at high concentrations is to assume sigmoidal kinetics and use the Hill equation (Miller et al., 1991). With 3 parameters, the Hill equation adds complexity to a model, and there was no evidence of saturation in our curve of TAG arteriovenous difference versus $[\mathrm{TAG}]_{\mathrm{A}}$ (data not shown). The positive effect of $[\mathrm{TAG}]_{\mathrm{A}}$ on clearance was thus accommodated empirically with 1 parameter, as

$$
\mathrm{Cl}=\mathrm{b}_{0}+\mathrm{b}_{1} \mathrm{~F}+\mathrm{b}_{2}[\mathrm{TAG}]_{\mathrm{A}},
$$

to produce model $2 \mathrm{~b}$.

Model 1, accounting for between-cow variation, explained only $10 \%$ of the total variation in TAG extraction, and had a prediction error equal to $24.2 \%$ of the mean observed extraction (Table 5). Models 2 and 3 did not account for any of the variation in TAG extraction. Henri-Michaelis-Menten parameters of model 4 were not identifiable from the data set. The increase in TAG clearance as $[\mathrm{TAG}]_{\mathrm{A}}$ increased is not consistent with saturation kinetics. Although we and others (Gagliostro et al., 1991; Miller et al., 1991) did not detect saturable extraction of TAG, Baldwin et al. (1980) reported saturation when $[\mathrm{TAG}]_{\mathrm{A}}$ increased to $1000 \mu \mathrm{M}$ on diets of $12 \%$ rumen-protected fat.

Model $2 \mathrm{~b}$, with $[\mathrm{TAG}]_{\mathrm{A}}$ as a positive effector of TAG extraction, explained $77 \%$ of the variance in TAG extraction between cows and $16 \%$ within cows, for a total $\mathrm{R}^{2}$ of 0.22 and prediction error of $22.5 \%$ of the mean. The Pearson correlation of 0.47 between predicted and observed TAG extraction was decreased $21 \%$ by bias to produce the CCC of 0.37 . Compared with fits to acetate and glucose extraction data, the $\mathrm{R}^{2}$ and $\mathrm{CCC}$ for prediction of TAG extraction were low. However, the standard deviation of TAG extraction was also less (Table 1), so prediction error for TAG extraction, as a percentage of the mean, was lower than for glucose extraction.

\section{LCFA}

Whereas TAG extraction represents extracellular hydrolysis by LPL, LCFA extraction represents net uptake into mammary cells of fatty acids released by LPL or arriving as fatty acids from the arterial circulation. Uptakes of LCFA were linearly related to $[\mathrm{LCFA}]_{\mathrm{A}}\left(\right.$ coefficient $=2.6$, partial $\left.\mathrm{R}^{2}=0.72\right)$ and $\mathrm{F}($ coefficient $=57$, partial $\mathrm{R}^{2}=0.09$ ), and clearances were related to $\mathrm{F}$ (coefficient $=0.31$, partial $\mathrm{R}^{2}=0.08$ ) and $[\mathrm{LCFA}]_{\mathrm{A}}$ (coefficient $=0.0038$, partial $\mathrm{R}^{2}=0.06$ ). A positive effect of $[\mathrm{LCFA}]_{\mathrm{A}}$ on LCFA clearance has a similar origin to that for TAG: sigmoidal kinetics of uptake. The coefficient of the $[\mathrm{LCFA}]_{\mathrm{A}}$ effect on LCFA clearance was 20 times smaller than the $[\mathrm{TAG}]_{\mathrm{A}}$ effect

Table 4. Parameters and statistics of best fits of models 1 to 4 to glucose extraction data from 4 cows $(\mathrm{n}=96)$

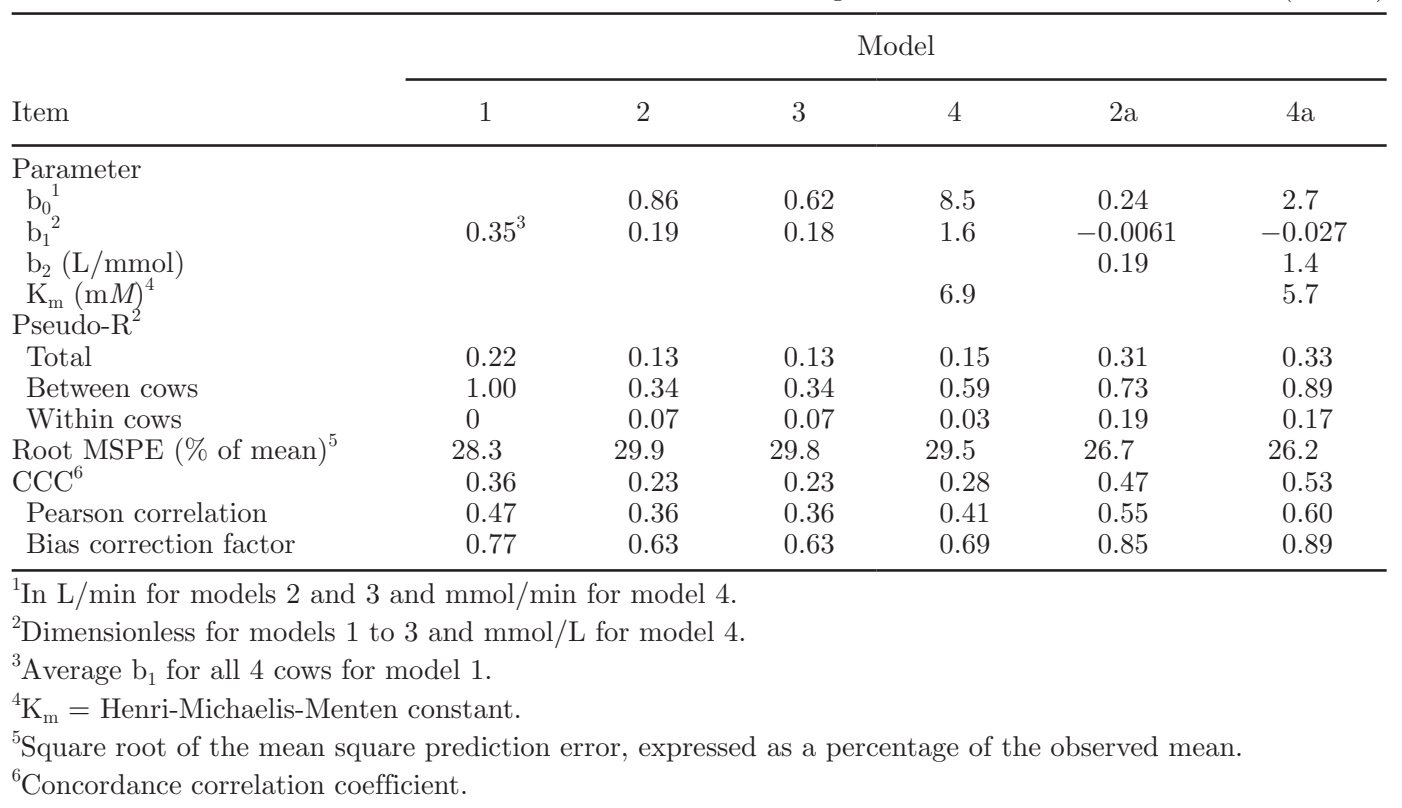


Table 5. Parameters and statistics of best fits of models 1 to 4 to triacylglycerol extraction data from 4 cows $(\mathrm{n}=96)$

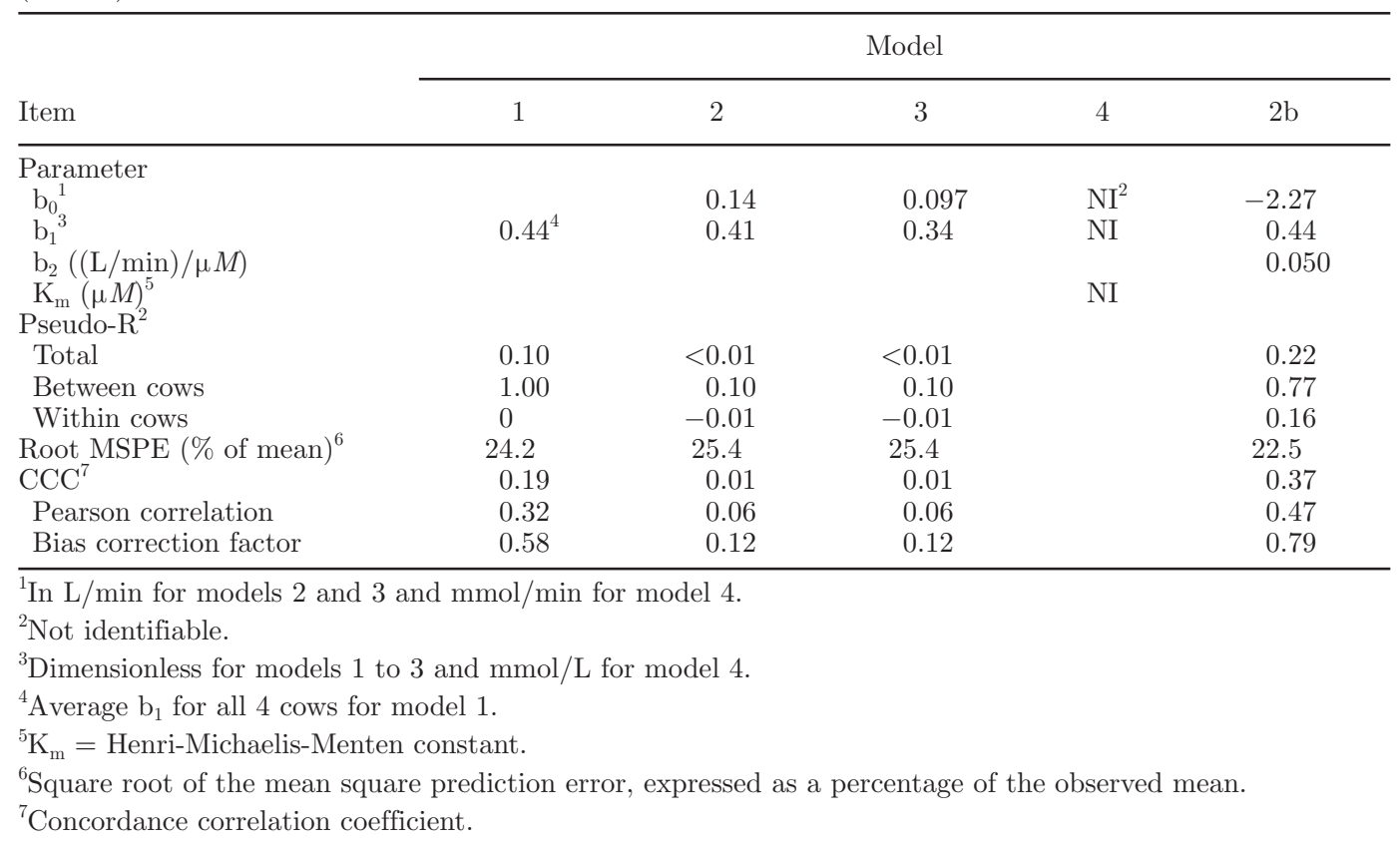

on TAG clearance. Although this statistic suggests that the effect of $[\mathrm{LCFA}]_{\mathrm{A}}$ may be negligible, a variant of model 2 , designated $2 \mathrm{c}$, included $[\mathrm{LCFA}]_{\mathrm{A}}$ as a linear effector of clearance, as

$$
\mathrm{Cl}=\mathrm{b}_{0}+\mathrm{b}_{1} \mathrm{~F}+\mathrm{b}_{2}[\mathrm{LCFA}]_{\mathrm{A}} .
$$

A constant LCFA extraction for each cow explained $19 \%$ of the total variation in LCFA extraction (Table 6). Models 2 and 3 explained $75 \%$ of the variation between cows and $14 \%$ within cows, for a total $\mathrm{R}^{2}$ of 0.26 . Model 4 parameters were unidentifiable, as for TAG extraction, indicating no saturation of LCFA uptake within the observed range of $[\mathrm{LCFA}]_{\mathrm{A}}$. Model $2 \mathrm{c}$, with $[\mathrm{LCFA}]_{\mathrm{A}}$ as a positive effector of clearance, explained $85 \%$ of the variation between cows and $16 \%$ within, for a total $\mathrm{R}^{2}$ of 0.29 . Prediction error was lowest with model $2 \mathrm{c}$ at $20.9 \%$ of the mean. The CCC was highest at 0.46 , with a mild bias correction of 0.84 . Thus, consideration of $[\mathrm{LCFA}]_{\mathrm{A}}$ in clearance model $2 \mathrm{c}$ improved the fit of model 2 to the observations.

\section{Comparison of Compartmental and Cylindrical Models}

Two different representations of the architecture of the capillary bed in which nutrient exchange between blood and tissue occurs were tested and found to describe the data equally well. Model 3 is based on uptake along the length of parallel, cylindrical capillaries into which total MBF is distributed equally, where there is a finite transit time for uptake to occur. A variable $\mathrm{F}$ was accommodated by allowing total capillary volume to vary with F (Eq. [14]). An alternative to assuming distributed-in-space uptake is to aggregate the whole capillary bed. Capillaries often form close-knit networks (Matsumoto et al., 1992; Prosser et al., 1996) in which there is extensive mixing of fluids and where several capillaries may be serving a common extravascular space (Wang and Bassingthwaighte, 2001). The assumption that a bolus dose of extracellular indicator injected into the mammary arterial supply distributes instantaneously into the entire extracellular space of the bovine mammary glands was used to fit 90 -s venous concentration profiles of the indicator with $\mathrm{R}^{2}>0.99$ (Qiao et al., 2005a). If the well-mixed compartment is adequate to describe non-steady-state behavior, then it should be suitable in the steady state. Model 2 is based on the single, well-mixed compartmental model of Hanigan et al. (1998), solved for steady-state conditions. Arterial metabolites mix instantaneously with the entire compartment volume, which is drained, and therefore sampled, by the subcutaneous mammary abdominal vein. Equation [12] was added to the model, expressing the assumption that $\mathrm{F}$ affects the volume of the extracellular compartment.

Although extraction Eq. [13] and [15] for models 2 and 3 , respectively, are not mathematically equivalent, the fits to extraction data were indistinguishable in goodness. Across all 4 metabolites, whether saturation 
Table 6. Parameters and statistics of best fits of models 1 to 4 to long-chain fatty acid extraction data from 4 cows $(\mathrm{n}=96)$

\begin{tabular}{|c|c|c|c|c|c|}
\hline \multirow[b]{2}{*}{ Item } & \multicolumn{5}{|c|}{ Model } \\
\hline & 1 & 2 & 3 & 4 & $2 \mathrm{c}$ \\
\hline \multicolumn{6}{|l|}{ Parameter } \\
\hline $\mathrm{b}_{0_{2}}^{1}$ & & 2.33 & 1.32 & $\mathrm{NI}^{2}$ & 1.55 \\
\hline $\mathrm{b}_{1}^{3}$ & $0.67^{4}$ & 0.22 & 0.26 & NI & 0.24 \\
\hline $\mathrm{b}_{2}[(\mathrm{~L} / \min ) / \mu M]$ & & & & & 0.0036 \\
\hline \multirow{2}{*}{\multicolumn{6}{|c|}{ Pseudo-R ${ }^{2}$}} \\
\hline & & & & & \\
\hline Total & 0.19 & 0.26 & 0.25 & & 0.29 \\
\hline Between cows & 1.00 & 0.75 & 0.74 & & 0.85 \\
\hline Within cows & 0 & 0.14 & 0.14 & & 0.16 \\
\hline Root MSPE (\% of mean $)^{6}$ & 22.4 & 21.5 & 21.5 & & 20.9 \\
\hline $\mathrm{CCC}^{7}$ & 0.31 & 0.41 & 0.41 & & 0.46 \\
\hline Pearson correlation & 0.43 & 0.50 & 0.50 & & 0.54 \\
\hline Bias correction factor & 0.72 & 0.80 & 0.81 & & 0.84 \\
\hline \multicolumn{6}{|c|}{ 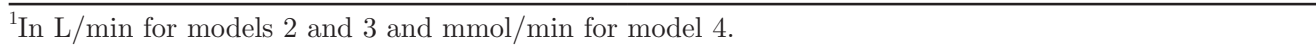 } \\
\hline \multicolumn{6}{|c|}{${ }^{2}$ Not identifiable. } \\
\hline \multicolumn{6}{|c|}{${ }^{3}$ Dimensionless for models 1 to 3 and mmol/L for model 4 . } \\
\hline \multicolumn{6}{|c|}{${ }^{4}$ Average $b_{1}$ for all 4 cows for model 1} \\
\hline \multicolumn{6}{|c|}{${ }^{5} \mathrm{~K}_{\mathrm{m}}=$ Henri-Michaelis-Menten constant. } \\
\hline
\end{tabular}

kinetics were apparent or not, regardless of the size of effects of $\mathrm{F}$ and $[\mathrm{S}]_{\mathrm{A}}$ on uptake and clearance, $\mathrm{R}^{2}$-values and prediction errors between and within cows were the same for models 2 and 3 (Tables 3 to 6 ). Thus, it is not possible from our data to declare one set of underlying assumptions regarding capillary architecture and exchange superior to the other. We conclude that steady-state arteriovenous differences across the bovine mammary glands can be described equally by compartmental and cylindrical capillary models. The compartmental model is easier to solve and to incorporate into larger models of milk synthesis or metabolism and, for these reasons, may be preferred. When we introduced additional independent variables into the uptake models to account for variation in uptake, we chose to follow the compartmental approach.

\section{Combined Fit to All Metabolites}

Compartmental models $2 \mathrm{a}$ and $2 \mathrm{c}$ that were identified as best fitting glucose and LCFA extractions, respectively, contained dependencies on $2 \mathrm{C}$ uptake and $[\mathrm{TAG}]_{\mathrm{V}}$, respectively, that would not normally be available as inputs. However, they are predicted with models for $2 \mathrm{C}$ and TAG extraction. If effects of $\mathrm{F}$ on extracellular volumes are similar across metabolites, predictions of the different metabolite uptakes will contain interdependencies of parameter values, so the 4 best models were fit to the extraction data for all 4 metabolites simultaneously. Except for glucose, fits obtained by minimizing RSS weighted for TSS within each metabolite (Table 7) were not substantially different from those obtained individually (Tables 3 to 6). The $\mathrm{K}_{\mathrm{m}}$ for $[2 \mathrm{C}]_{\mathrm{V}}$ in $2 \mathrm{C}$ uptake was $0.36 \mathrm{~m} M$ compared with $0.44 \mathrm{mM}$ previously. Both TAG and LCFA parameters were relatively unchanged. However, all 3 of the glucose parameters were substantially different in the combined model.

Of all the metabolite extractions, variation in $2 \mathrm{C}$ extraction was best explained with $\mathrm{R}^{2}=0.82$ (Table 7), whereas less than $30 \%$ of variation in glucose, TAG, or LCFA extraction was accounted for. The greatest difficulty lay in explaining within-cow variation, because 77 to $99 \%$ of between-cow variation was accounted for. Glucose extraction was the worst fit, with only $5 \%$ of variation within cows accounted for by the model. For TAG and LCFA extraction, only 14 and $16 \%$, respectively, of variation within cows was explained. These low goodnesses-of-fit are surprising because within-cow variation includes the effects of the blood flow inhibitors that were infused for $60 \mathrm{~min}$ in the middle of 140 min of sample collection. To test whether the effects of $\mathrm{F}$ and $[\mathrm{S}]_{\mathrm{A}}$ were completely accounted for in the fitted models, residual extractions for each metabolite after prediction were regressed against $\mathrm{F}$ or $[\mathrm{S}]_{\mathrm{A}}$ (data not shown). None of the slopes were different from zero $(P>0.36)$, indicating that unexplained variation was not related to effects of $\mathrm{F}$ or $[\mathrm{S}]_{\mathrm{A}}$ not accounted for in the models. Furthermore, regression of observed extractions against predicted (Figure 2) did not dif- 
fer in slope or intercept from the concordance line of unity. Similarly, bias corrections for the CCC were mild (Table 7). These statistics indicate that prediction error was random, not biased, and effects of $\mathrm{F}$ and $[\mathrm{S}]_{\mathrm{A}}$ were properly accounted for with optimized parameter values. According to the Shapiro-Wilk test, residual errors were normally distributed for all metabolites except TAG $(P<0.01)$ but this finding does not influence parameter estimates and likely reflects the use of blood flow inhibitors to perturb $\mathrm{F}$ instead of sampling $\mathrm{F}$ values randomly from a population. The low withincow $R^{2}$ values suggest that factors other than $F$ and $[\mathrm{S}]_{\mathrm{A}}$ are responsible for most of the minute-to-minute variation in metabolite extraction across the mammary glands of an individual cow. Such factors could include perturbations in alveolar milk synthesis rates or heterogeneity of blood flow induced by variation in posture or external environmental stressors. Technical variation in the estimation of $\mathrm{F}$ by dye dilution would also be included in the prediction error. Overall, 22 to $82 \%$ of variation in mammary extraction of energy metabolites from plasma by 4 cows was accounted for when $\mathrm{MBF}$ was manipulated over a $50 \%$ range by inhibition of local blood flow control systems.

After fitting the combined model to extraction data for all 4 metabolites simultaneously, the fitted equations were used to predict uptakes as

$$
\text { uptake }=\mathrm{F} \cdot[\mathrm{S}]_{\mathrm{A}} \cdot \text { extraction, }
$$

and goodnesses-of-fit were assessed. Here, a substantial proportion of variation between and within cows was accounted for. Values of $\mathrm{R}^{2}$ within cow ranged from 0.40 to 0.73 , and were highest for TAG and LCFA. Values between cows ranged from 0.66 to 0.99 and were highest for $2 \mathrm{C}$, glucose, and LCFA. The combined model accounted for approximately one-half of the total variation in $2 \mathrm{C}$ and glucose uptakes, and approximately three-fourths of the total variation in TAG and LCFA uptakes. Bias correction was again mild, and slopes and intercepts of regression lines between observed and predicted uptakes (Figure 3) were not different from the line of unity $(P>0.21)$.

Table 7. Parameters and statistics of best combined fit of all models to metabolite extraction data, and statistics of fits to uptake data $(\mathrm{n}=96)$

\begin{tabular}{|c|c|c|c|c|}
\hline \multirow[b]{2}{*}{ Item } & \multicolumn{4}{|c|}{ Metabolite and model } \\
\hline & $\begin{array}{c}2 \mathrm{C} \\
\text { (model } 4)\end{array}$ & $\begin{array}{c}\text { Glucose } \\
\text { (model 2a) }\end{array}$ & $\begin{array}{c}\text { TAG } \\
\text { (model } 2 \mathrm{~b})\end{array}$ & $\begin{array}{c}\text { LCFA } \\
(\text { model } 2 \mathrm{c})\end{array}$ \\
\hline \multicolumn{5}{|l|}{ Parameter } \\
\hline $\mathrm{b}_{0}{ }^{1}$ & 3.35 & -0.32 & -2.29 & 1.77 \\
\hline $\mathrm{b}_{1}{ }^{2}$ & 1.42 & -0.090 & 0.44 & 0.24 \\
\hline $\mathrm{b}_{2}{ }^{3}$ & & 0.30 & 0.050 & 0.0025 \\
\hline $\mathrm{K}_{\mathrm{m}}(\mathrm{m} M)^{4}$ & 0.36 & & & \\
\hline \multicolumn{5}{|l|}{ Fits to extraction data } \\
\hline \multicolumn{5}{|l|}{ Pseudo- $\mathrm{R}^{2}$} \\
\hline Total & 0.82 & 0.25 & 0.22 & 0.28 \\
\hline Between cows & 0.99 & 0.98 & 0.77 & 0.84 \\
\hline Within cows & 0.48 & 0.05 & 0.16 & 0.14 \\
\hline Root MSPE (\% of mean $)^{5}$ & 15.3 & 27.6 & 22.5 & 21.2 \\
\hline $\mathrm{CCC}^{6}$ & 0.89 & 0.41 & 0.37 & 0.43 \\
\hline Pearson correlation & 0.90 & 0.50 & 0.47 & 0.52 \\
\hline Bias correction factor & 0.99 & 0.82 & 0.79 & 0.83 \\
\hline \multicolumn{5}{|l|}{ Fits to uptake data } \\
\hline \multicolumn{5}{|l|}{ Pseudo- $\mathrm{R}^{2}$} \\
\hline Total & 0.52 & 0.42 & 0.73 & 0.77 \\
\hline Between cows & 0.88 & 0.94 & 0.66 & 0.99 \\
\hline Within cows & 0.42 & 0.40 & 0.73 & 0.70 \\
\hline Root MSPE ( $\%$ of mean) & 18.7 & 28.4 & 22.6 & 32.4 \\
\hline $\mathrm{CCC}$ & 0.67 & 0.55 & 0.83 & 0.88 \\
\hline Pearson correlation & 0.72 & 0.64 & 0.86 & 0.88 \\
\hline Bias correction factor & 0.93 & 0.86 & 0.97 & 1.00 \\
\hline
\end{tabular}

${ }^{1} \mathrm{In} \mathrm{mmol} / \mathrm{min}$ for $2 \mathrm{C}$ (acetate $+\beta$-hydroxybutyrate) and $\mathrm{L} / \mathrm{min}$ for other metabolites.

${ }^{2} \mathrm{In} \mathrm{mmol} / \mathrm{L}$ for $2 \mathrm{C}$ and dimensionless for other metabolites.

${ }^{3} \mathrm{In} \mathrm{L} / \mathrm{mmol}$ for glucose and $(\mathrm{L} / \mathrm{min}) / \mu M$ for triacylglycerol (TAG) and long-chain fatty acids (LCFA).

${ }^{4} \mathrm{~K}_{\mathrm{m}}=$ Henri-Michaelis-Menten constant.

${ }^{5}$ Square root of the mean square prediction error, expressed as a percentage of the observed mean.

${ }^{6}$ Concordance correlation coefficient. 
Better fits to uptake observations, versus extraction observations, are due to removal of some of the effect of technical error in estimating $\mathrm{F}$, because $\mathrm{F}$, regardless of precision, is a factor in the calculation of uptake. The input of $\mathrm{F}$ as a driving variable for the model provides information about variation in uptake estimates that does not also apply to extraction. In addition, decreasing $\mathrm{F}$ with inhibitors of the NOS and COX systems for regulating MBF depressed some uptakes of energy metabolites without increasing extraction (Madsen et al., 2014). This effect was captured by the model and resulted in explanation of a greater proportion of uptake variance compared with extraction.

\section{Modeling the Effect of $F$}

The main purpose of the current work was to evaluate approaches to include a variable $\mathrm{F}$ in predictions of net uptake of energy metabolites by the mammary glands of lactating cows. To generate the data that were used to test models, Madsen et al. (2014) inhibited mammary endothelial NOS and COX that are central to linking $\mathrm{F}$ with metabolic activity in multiple tissues, including skeletal muscle, kidney, and mammary glands
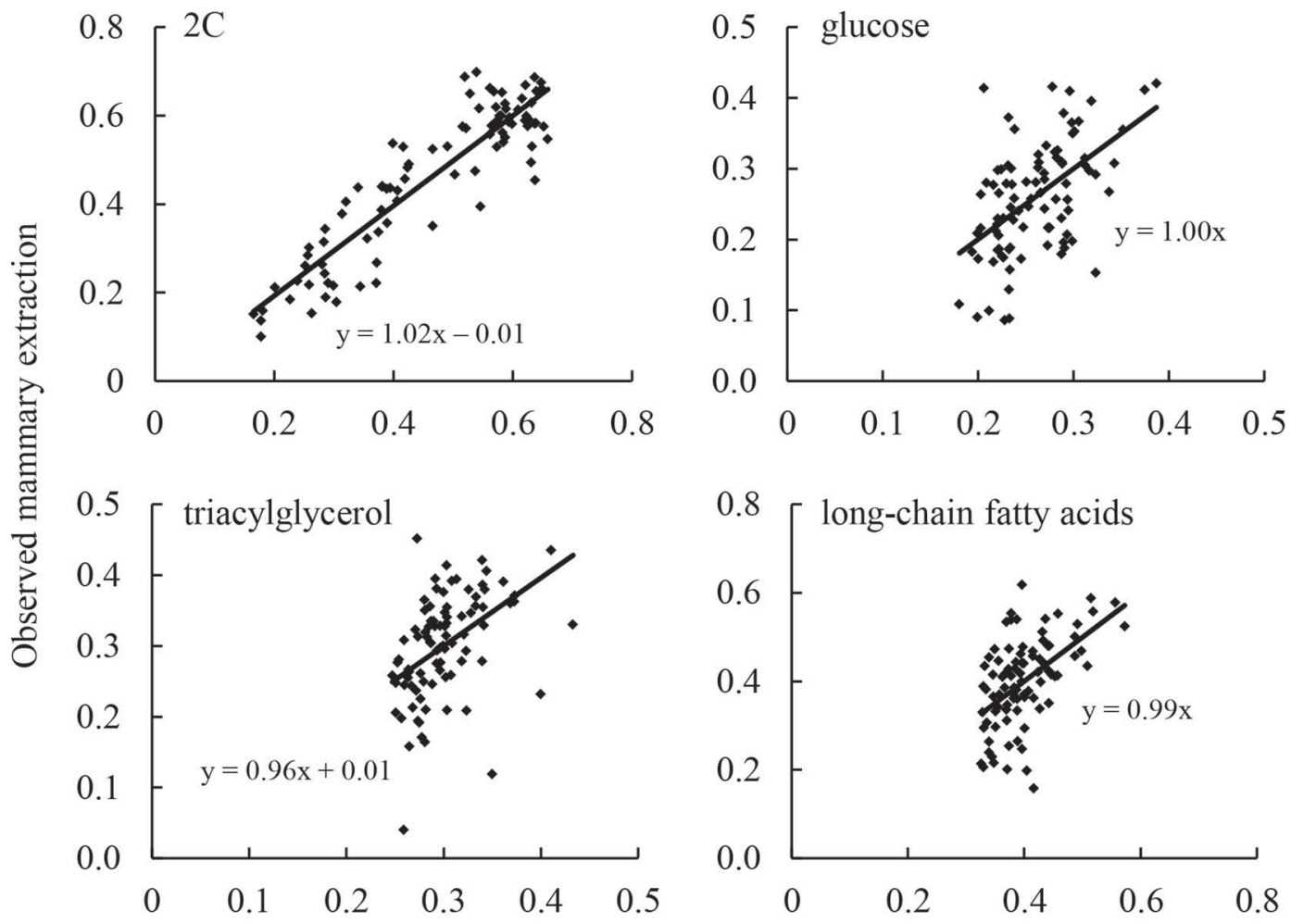

Predicted mammary extraction

Figure 2. Observed extractions of energy metabolites plotted against those predicted with the combined model fit to all metabolites at once. $2 \mathrm{C}=$ acetate $+\beta$-hydroxybutyrate. 

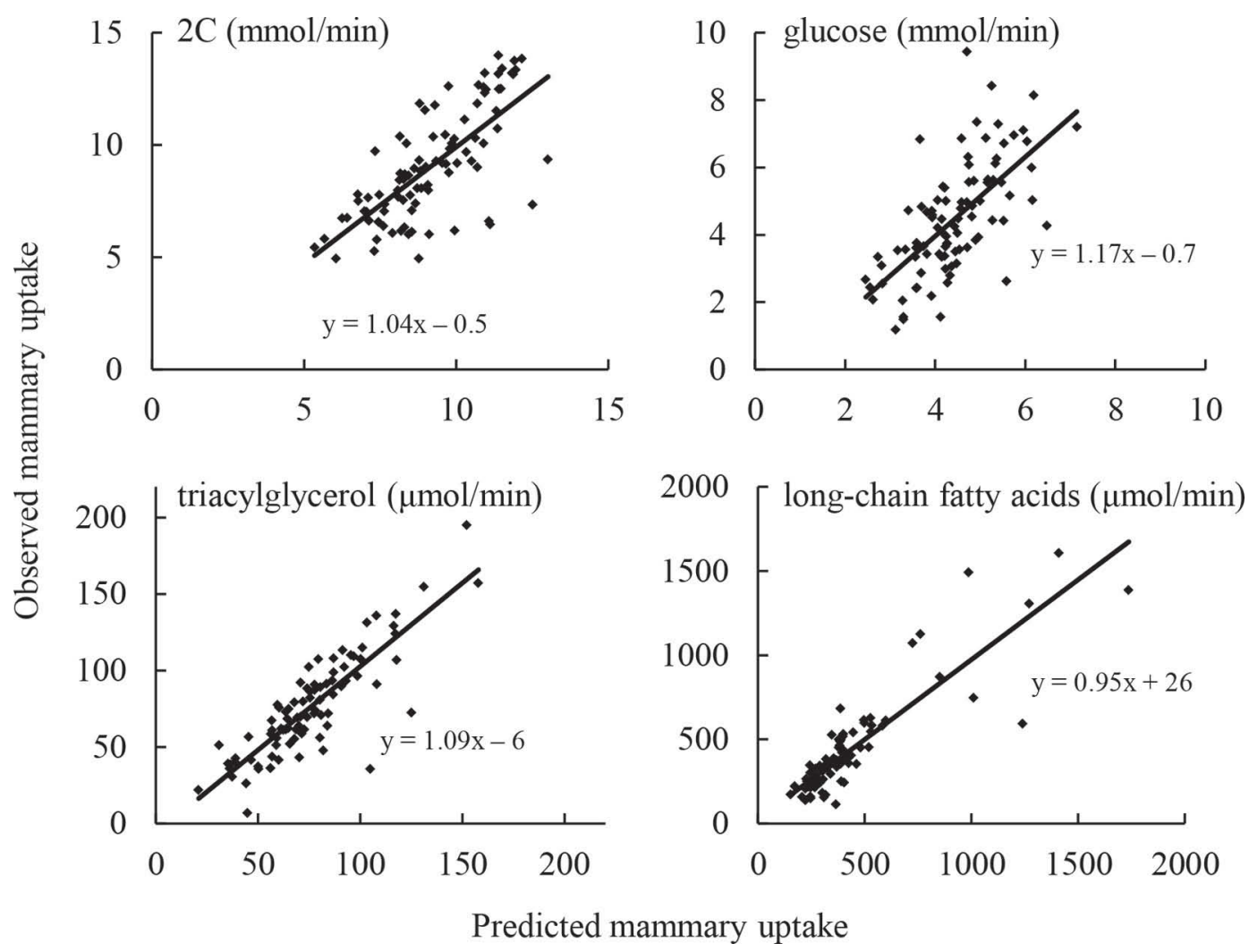

Figure 3. Observed uptakes of energy metabolites plotted against those predicted with the combined model fit to all metabolites at once. $2 \mathrm{C}=$ acetate $+\beta$-hydroxybutyrate.

not decrease capillary transit time to the detriment of net uptakes (Cant and McBride, 1995). In a well-mixed compartmental model of the extracellular space, capillary recruitment can be accommodated by changing $\mathrm{Vol}_{e}$, which affects $\mathrm{Cl}$ because $\mathrm{Cl}$ is volume-dependent, expressed in units of volume/time. Recently, Poole et al. (2013) suggested that capillary recruitment primarily involves utilization of a greater proportion of the endothelial exchange surface and diffusion capacity further down the length of capillaries, as opposed to opening up those previously closed to flow. This type of recruitment might be accommodated in a compartmental representation of the extracellular space by either changing $\mathrm{Vol}_{\mathrm{e}}$ or the rate constant $\mathrm{k}$ for fractional net uptake from the compartment. Clearance is actually the product of these 2 variables (Eq. [3]) and the arteriovenous difference data we were using do not provide enough information to decompose $\mathrm{Cl}$ into $\mathrm{k}$ and $\mathrm{Vol}_{\mathrm{e}}$ separately. Thus, both descriptions of capillary recruitment are accommodated by setting $\mathrm{Cl}$ as a function of $\mathrm{F}$ as in model 2 (Eq. [12]). The assumption in model 4 is that capillary recruitment exposes a greater number of mammary cells to vascular metabolites and, therefore, $\mathrm{V}_{\max }$ is a function of $\mathrm{F}$ (Eq. 17).
If all 4 of the metabolites under study here distributed throughout the same extracellular space, then estimates of the effect of $\mathrm{F}$ on $\mathrm{Vol}_{\mathrm{e}}$ should be the same across metabolite fits. To test this proposition, the change in $\mathrm{Cl}$ or $\mathrm{V}_{\max }$ for a unit increase in $\mathrm{F}$ was calculated for each metabolite, using mean $\mathrm{F}$ and $[\mathrm{S}]_{\mathrm{A}}$ values from the whole data set as inputs to the combined model. These slopes were normalized to the mean $\mathrm{Cl}$ or $\mathrm{V}_{\max }$, respectively, to be comparable across metabolites. For each 1 $\mathrm{L} /$ min increase in $\mathrm{F}, 2 \mathrm{C} \mathrm{V}_{\max }$ increased $13 \%$, glucose $\mathrm{Cl}$ increased 14\%, TAG $\mathrm{Cl}$ increased $18 \%$, and LCFA $\mathrm{Cl}$ increased $7 \%$. It appears, then, that $\mathrm{F}$ increased the volume of distribution of $2 \mathrm{C}$ and glucose equally, TAG to a greater extent, and LCFA to a lesser extent. Clearance of TAG is unique because it takes place in the vascular space under the supervision of endothelial LPL. Lipoproteins can remain attached to LPL in the capillary for several minutes while lipolysis is ongoing (Ross et al., 2004; Hultin et al., 2013). The larger effect of $\mathrm{F}$ on distribution volume for TAG compared with the other metabolites suggests that capillary volume is increased to a greater extent than extracellular volume by local control of MBF. If multiple capillaries serve a common extracellular space, as the compartmental 
model assumes, then capillary recruitment could increase without changing $\mathrm{Vol}_{\mathrm{e}}$ as much.

The smaller effect of $\mathrm{F}$ on distribution volume for LCFA compared with $2 \mathrm{C}$ and glucose indicates that LCFA distribute into a different space. Long-chain fatty acids are bound to albumin in both vascular and extracellular spaces (van der Vusse, 2009). Arterially injected glucose, on the other hand, rapidly distributed into an extravascular space in the bovine mammary glands that was $34 \%$ larger than the extracellular volume, which was suggested to include an intracellular compartment associated with glucose transporters (Qiao et al., 2005b). Similarly, small, water-soluble solutes like acetate and BHB may freely access a portion of the intracellular space so that effects of $\mathrm{F}$ on volumes of $2 \mathrm{C}$ and glucose distribution are larger than effects on LCFA distribution.

\section{CONCLUSIONS}

Inhibition of vasodilatory pathways to depress MBF decreased net mammary clearances of energy metabolites from blood. The effect can be accommodated mathematically with $\mathrm{F}$ as a predictor of $\mathrm{Cl}$ in a single, compartmental model of the mammary extracellular space, or with $\mathrm{F}$ as a predictor of $\mathrm{k} \cdot \mathrm{Vol}_{\mathrm{c}}$ in a cylindrical model of the single capillary. Both approaches yielded the same goodness-of-fit to extraction efficiencies so they are equally capable of describing the effect of $\mathrm{F}$ on uptake. Using the compartmental model, saturable uptake of $2 \mathrm{C}$ was identified, with a $\mathrm{K}_{\mathrm{m}}$ of $0.4 \mathrm{mM}$ for venous $2 \mathrm{C}$. The $\mathrm{K}_{\mathrm{m}}$ for glucose in glucose uptake was estimated to be $5.7 \mathrm{mM}$, which is above the physiological range for venous glucose, so linear kinetics were adequate to model glucose uptake. Uptake of $2 \mathrm{C}$ was included in the glucose $\mathrm{Cl}$ model as a positive effector. Saturation parameters could not be found for TAG and LCFA. The combined fit of all 4 best-fit models to extraction data for all 4 metabolites at once explained 22 to $82 \%$ of variation in metabolite extraction, and 42 to $77 \%$ of variation in metabolite uptake. Eq. [7], [19], [22], [24], [25], and [26] constitute a full model that was able to predict responses to changing $\mathrm{MBF}$ in net mammary uptakes of $2 \mathrm{C}$, glucose, TAG, and LCFA.

\section{ACKNOWLEDGMENTS}

Financial support for this work was provided by NSERC, Ottawa, Canada. Torben Madsen was in receipt of a postgraduate award from the Faculty of Life Sciences, Copenhagen University, Denmark. Special thanks go to Bill Szkotnicki (University of Guelph, Guelph, ON, Canada) for maintenance of the computers and software used in the modelling analyses.

\section{REFERENCES}

Baldwin, R. L., N. E. Smith, J. Taylor, and M. Sharp. 1980. Manipulating metabolic parameters to improve growth rate and milk secretion. J. Anim. Sci. 51:1416-1428.

Bequette, B. J., M. D. Hanigan, A. G. Calder, C. K. Reynolds, G. E. Lobley, and J. C. MacRae. 2000. Amino acid exchange by the mammary gland of lactating goats when histidine limits milk production. J. Dairy Sci. 83:765-775.

Cant, J. P., E. J. DePeters, and R. L. Baldwin. 1993. Mammary uptake of energy metabolites in dairy cows fed fat and its relationship to milk protein depression. J. Dairy Sci. 76:2254-2265.

Cant, J. P., and B. W. McBride. 1995. Mathematical analysis of the relationship between blood flow and uptake of nutrients in the mammary glands of a lactating cow. J. Dairy Res. 62:405-422.

Cieslar, S. R. L., T. G. Madsen, N. G. Purdie, D. R. Trout, V. R. Osborne, and J. P. Cant. 2014. Mammary blood flow and metabolic activity are linked by a feed-back mechanism involving nitric oxide synthesis. J. Dairy Sci. 97:2090-2100.

Davis, S. R., and R. J. Collier. 1985. Mammary blood flow and regulation of substrate supply for milk synthesis. J. Dairy Sci. 68:10411058.

Delgado-Elorduy, A., C. B. Theurer, J. T. Huber, A. Alio, O. Lozano, M. Sadik, P. Cuneo, H. D. DeYoung, I. J. Simas, J. E. P. Santos, L. Nussio, C. Nussio, K. E. Webb, and H. Tagari. 2002. Splanchnic and mammary nitrogen metabolism by dairy cows fed dry-rolled or steam-flaked sorghum grain. J. Dairy Sci. 85:148-159.

Deussen, A., V. Ohanyan, A. Jannasch, L. Yin, and W. Chilian. 2012. Mechanisms of metabolic coronary flow regulation. J. Mol. Cell. Cardiol. 52:794-801.

Forsberg, N. E., R. L. Baldwin, and N. E. Smith. 1984. Roles of acetate and its interactions with glucose and lactate in cow mammary tissue. J. Dairy Sci. 67:2247-2254.

Forsberg, N. E., R. L. Baldwin, and N. E. Smith. 1985. Roles of glucose and its interactions with acetate in maintenance and biosynthesis in cow mammary tissue. J. Dairy Sci. 68:2544-2549.

Gagliostro, G., Y. Chilliard, and M.-J. Davicco. 1991. Duodenal rapeseed oil infusion in early and midlactation cows. 3. Plasma hormones and mammary apparent uptake of metabolites. J. Dairy Sci. 74:1893-1903.

Hanigan, M. D., J. France, D. Wray-Cahen, D. E. Beever, G. E. Lobley, L. Reutzel, and N. E. Smith. 1998. Alternative models for analyses of liver and mammary transorgan metabolite extraction data. Br. J. Nutr. 79:63-78.

Hellsten, Y., M. Nyberg, L. G. Jensen, and S. P. Mortensen. 2012. Vasodilator interactions in skeletal muscle blood flow regulation. J. Physiol. 590:6297-6305.

Hultin, M., R. Savonen, O. Chevreuil, and T. Olivecrona. 2013. Chylomicron metabolism in rats: kinetic modeling indicates that the particles remain at endothelial sites for minutes. J. Lipid Res. 54:2595-2605.

Kather, H., M. Rivera, and K. Brand. 1972. Interrelationship and control of glucose metabolism and lipogenesis in isolated fat-cells: control of pentose phosphate-cycle activity by cellular requirement for reduced nicotinamide adenine dinucleotide phosphate. Biochem. J. 128:1097-1102.

Lemosquet, S., G. Raggio, G. E. Lobley, H. Rulquin, J. Guinard-Flament, and H. Lapierre. 2009. Whole-body glucose metabolism and mammary energetic nutrient metabolism in lactating dairy cows receiving digestive infusions of casein and propionic acid. J. Dairy Sci. 92:6068-6082.

Lin, L. I.-K. 1989. A concordance correlation coefficient to evaluate reproducibility. Biometrics 45:255-268.

Linzell, J. L. 1974. Mammary blood flow and methods of identifying and measuring precursors of milk. Pages 143-225 in Lactation: A Comprehensive Treatise. Vol. 1. B. L. Larson and V. R. Smith, ed. Academic Press, New York, NY.

Linzell, J. L., and T. B. Mepham. 1974. Effects of intramammary arterial infusion of essential amino acids in lactating goat. J. Dairy Res. 41:101-109. 
Mackle, T. R., D. A. Dwyer, K. L. Ingvartsen, P. Y. Chouinard, D. A. Ross, and D. E. Bauman. 2000. Effects of insulin and postruminal supply of protein on use of amino acids by the mammary gland for milk protein synthesis. J. Dairy Sci. 83:93-105.

Madsen, T. G., S. R. L. Cieslar, D. R. Trout, M. O. Nielsen, and J. P. Cant. 2014. Rate of blood flow to the mammary glands affects uptakes of energy metabolites from blood. J. Dairy Sci. (accepted).

Matsumoto, M., H. Nishinakagawa, M. Kurohmaru, Y. Hayashi, and J. Otsuka. 1992. Pregnancy and lactation affect the microvasculature of the mammary gland in mice. J. Vet. Med. Sci. 54:937-943.

Miller, P. S., B. L. Reis, C. C. Calvert, E. J. DePeters, and R. L. Baldwin. 1991. Patterns of nutrient uptake by the mammary glands of lactating dairy cows. J. Dairy Sci. 74:3791-3799.

Neter, J., W. Wasserman, and M. H. Kutner. 1985. Applied Linear Statistical Models. 2nd ed. Irwin Professional Publ., Homewood, IL.

Nielsen, M. O., S. Nyborg, K. Jakobsen, I. R. Fleet, and J. Nørgaard. 2004. Mammary uptake and excretion of prostanoids in relation to mammary blood flow and milk yield during pregnancy-lactation and somatotropin treatment in dairy goats. Domest. Anim. Endocrinol. 27:345-362.

Nielsen, M. O., C. Schleisner, K. Jakobsen, and P. H. Andersen. 1995. The effect of mammary $\mathrm{O}_{2}$ uptake, $\mathrm{CO}_{2}$ and $\mathrm{H}^{+}$production on mammary blood flow during pregnancy, lactation and somatotropin treatment in goats. Comp. Biochem. Physiol. 112A:591-599.

Poole, D. C., S. W. Copp, S. K. Ferguson, and T. I. Musch. 2013. Skeletal muscle capillary function: Contemporary observations and novel hypotheses. Exp. Physiol. 98:1645-1658.

Prosser, C. G., S. R. Davis, V. C. Farr, and P. Lacasse. 1996. Regulation of blood flow in the mammary microvasculature. J. Dairy Sci. 79:1184-1197.

Qiao, F., D. R. Trout, V. M. Quinton, and J. P. Cant. 2005a. A compartmental capillary, convolution integration model to investigate nutrient transport and metabolism in vivo from paired indicator/ nutrient dilution curves. J. Appl. Physiol. 99:788-798.

Qiao, F., D. R. Trout, C. Xiao, and J. P. Cant. 2005b. Kinetics of glucose transport and sequestration in lactating bovine mammary glands measured in vivo with a paired indicator/nutrient dilution technique. J. Appl. Physiol. 99:799-806.

Renkin, E. M. 1984. Control of microcirculation and blood-tissue exchange. Pages 627-687 in The Cardiovascular System. E. M. Renkin, and C. C. Michel, ed. American Physiological Society, Bethesda, MD.

Rigout, S., S. Lemosquet, J. E. Van Eys, J. W. Blum, and H. Rulquin. 2002. Duodenal glucose increases glucose fluxes and lactose synthesis in grass silage-fed dairy cows. J. Dairy Sci. 85:595-606.

Ross, A. C., A. M. G. Pasatiempo, and M. H. Green. 2004. Chylomicron margination, lipolysis, and vitamin A uptake in the lactating rat mammary gland: Implications for milk retinoid content. Exp. Biol. Med. (Maywood) 229:46-55.

Safayi, S., and M. O. Nielsen. 2013. Intravenous supplementation of acetate, glucose or essential amino acids to an energy and protein deficient diet in lactating dairy goats: Effects on milk production and mammary nutrient extraction. Small Rumin. Res. 112:162173.

Triggle, C. R., S. M. Samuel, S. Ravishankar, I. Marei, G. Arunachalam, and H. Ding. 2012. The endothelium: Influencing vascular smooth muscle in many ways. Can. J. Physiol. Pharmacol. 90:713738 .

van der Vusse, G. J. 2009. Albumin as fatty acid transporter. Drug Metab. Pharmacokinet. 24:300-307.

Wang, C. Y., and J. B. Bassingthwaighte. 2001. Capillary supply regions. Math. Biosci. 173:103-114.

Xiao, C. T., and J. P. Cant. 2005. Relationship between glucose transport and metabolism in isolated bovine mammary epithelial cells. J. Dairy Sci. 88:2794-2805.

\section{APPENDIX}

A combination of all best-fit extraction equations was fit simultaneously by solving the following equations in the order given. Inputs are $\mathrm{F}$ and arterial concentrations $[2 \mathrm{C}]_{\mathrm{A}},[\text { glucose }]_{\mathrm{A}},[\mathrm{TAG}]_{\mathrm{A}}$, and $[\mathrm{NEFA}]_{\mathrm{A}} ; \mathrm{ex}=$ extraction, glc $=$ glucose, up $=$ uptake.

$$
\begin{aligned}
& \mathrm{ex}_{2 \mathrm{C}}=1+\frac{\mathrm{b}_{0,2 \mathrm{C}}+\mathrm{b}_{1,2 \mathrm{C}} \mathrm{F}+\mathrm{K}_{\mathrm{m}, 2 \mathrm{C}} \mathrm{F}-[2 \mathrm{C}]_{\mathrm{A}} \mathrm{F}-\sqrt{\left(\mathrm{b}_{0,2 \mathrm{C}}+\mathrm{b}_{1,2 \mathrm{C}} \mathrm{F}+\mathrm{K}_{\mathrm{m}, 2 \mathrm{C}} \mathrm{F}-[2 \mathrm{C}]_{\mathrm{A}} \mathrm{F}\right)^{2}+4[2 \mathrm{C}]_{\mathrm{A}} \mathrm{F}^{2} \mathrm{~K}_{\mathrm{m}, 2 \mathrm{C}}}}{2[2 \mathrm{C}]_{\mathrm{A}} \mathrm{F}}, \\
& \mathrm{up}_{2 \mathrm{C}}=\mathrm{F} \cdot[2 \mathrm{C}]_{\mathrm{A}} \cdot \mathrm{ex}_{2 \mathrm{C}}, \\
& \mathrm{ex}_{\mathrm{glc}}=\frac{\mathrm{b}_{0, \mathrm{glc}}+\mathrm{b}_{1, \mathrm{glc}} \mathrm{F}+\mathrm{b}_{2, \mathrm{glc}} \mathrm{up}_{2 \mathrm{C}}}{\mathrm{b}_{0, \mathrm{glc}}+\mathrm{b}_{1, \mathrm{glc}} \mathrm{F}+\mathrm{b}_{2, \mathrm{glc}} \mathrm{up}_{2 \mathrm{C}}+\mathrm{F}}, \\
& \mathrm{ex}_{\mathrm{TAG}}=\frac{\mathrm{b}_{0, \mathrm{TAG}}+\mathrm{b}_{1, \mathrm{TAG}} \mathrm{F}+\mathrm{b}_{2, \mathrm{TAG}}[\mathrm{TAG}]_{\mathrm{A}}}{\mathrm{b}_{0, \mathrm{TAG}}+\mathrm{b}_{1, \mathrm{TAG}} \mathrm{F}+\mathrm{b}_{2, \mathrm{TAG}}[\mathrm{TAG}]_{\mathrm{A}}+\mathrm{F}}, \\
& \mathrm{LCFA}_{\mathrm{A}}=3[\mathrm{TAG}]_{\mathrm{A}} \mathrm{ex}_{\mathrm{TAG}}+[\text { fatty acids }]_{\mathrm{A}}, \\
& \operatorname{ex}_{\mathrm{LCFA}}=\frac{\mathrm{b}_{0, \mathrm{LCFA}}+\mathrm{b}_{1, \mathrm{LCFA}} \mathrm{F}+\mathrm{b}_{2, \mathrm{LCFA}}[\mathrm{LCFA}]_{\mathrm{A}}}{\mathrm{b}_{0, \mathrm{LCFA}}+\mathrm{b}_{1, \mathrm{LCFA}} \mathrm{F}+\mathrm{b}_{2, \mathrm{LCFA}}[\mathrm{LCFA}]_{\mathrm{A}}+\mathrm{F}} .
\end{aligned}
$$

